\section{Well-Ordered Mesoporous Silica Nanoparticles as Cell Markers}

Yu-Shen Lin, ${ }^{\dagger}$ Chih-Pin Tsai, ${ }^{\dagger}$ Hsing-Yi Huang, ${ }^{\dagger}$

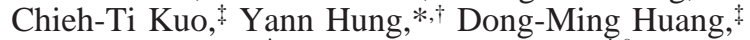
Yao-Chang Chen, ${ }^{\ddagger}$ and Chung-Yuan Mou ${ }^{\dagger, \S}$

\section{Department of Chemistry, National Taiwan University, Taipei, Taiwan 106, Stem Cell Research Center, National Health Research Institutes, Taipei, Taiwan 115, and Center for Condensed Matter Sciences, National Taiwan University, Taipei, Taiwan 106}

Received May 13, 2005 Revised Manuscript Received July 5, 2005

The application of nanomaterials in medical and biological fields has drawn great research interest in recent years. ${ }^{1}$ Currently, nanoparticles have been used in many biological fields, such as sensors, fluorescent markers in vitro and in vivo, clinical diagnosis, drug delivery, and MRI contrast agents. $^{2-8}$ Mesoporous materials, especially MCM-type silica, have many unique properties, such as ordered porous structure, extremely high surface area $\left(>1000 \mathrm{~m}^{2} \mathrm{~g}^{-1}\right)$, large pore volume, and well-defined and tunable pore size $(1.5-10 \mathrm{~nm})$. It is proposed that mesoporous materials can act as a convenient reservoir for drugs and biomolecules. The drug adsorbing and releasing behavior of porous silica has been extensively studied using ibuprofen as a model drug. ${ }^{9}$ Lin and co-workers ${ }^{10}$ used $\mathrm{CdS}$ as a gate to demonstrate the stimuli-responsive controlled release in MCM-41, and Tanaka et al. ${ }^{11}$ demonstrated photocontrolled releasing

* Corresponding author e-mail: yannhung@ntu.edu.tw.

$\dagger$ Department of Chemistry, National Taiwan University.

¥ National Health Research Institutes.

$\S$ Center for Condensed Matter Sciences, National Taiwan University.

(1) (a) Parak, W. J.; Gerion, D.; Pellegrino, T.; Zanchet, D.; Micheel, C.; Williams, S. C.; Boudreau, R.; Le Gros, M. A.; Larabell, C. A.; Alivisatos, A. P. Nanotechnology 2003, 14, R15. (b) Michalet, X.; Pinaud, F. F.; Bentolila, L. A.; Tsay, J. M.; Doose, S.; Li, J. J.; Sundaresan, G.; Wu, A. M.; Gambhir, S. S.; Weiss, S. Science 2005, 307, 538. (c) Pankhurst, Q. A.; Connolly, J.; Jones, S. K.; Dobson, J. J. Phys. D: Appl. Phys. 2003, 36, R167.

(2) Larson, D. R.; Zipfel, W. R.; Williams, R. M.; Clark, S. W.; Bruchez, M. P.; Wise, F. W.; Webb, W. W. Science 2003, 300, 1434.

(3) Elghanian, R.; Storhoff, J. J.; Mucic, R. C.; Letsinger, R. L.; Mirkin, C. A. Science 1997, 277, 1078.

(4) Babes, L.; Denizot, B.; Tanguy, G.; Le Jeune, J. J.; Jallet, P. J. J. Colloid Interface Sci. 1999, 212, 474.

(5) Saviæ, R.; Luo, L.; Eisenberg, A.; Maysinger, D. Science 2003, 300 , 615 .

(6) Bianco, A.; Kostarelos, K.; Partidos, C. D.; Prato, M. Chem. Commun, 2005, 571.

(7) Foley, S.; Crowley, C.; Smaihi, M.; Bonfils, C.; Erlanger, B. F.; Seta, P.; Larroque, C. Biochem. Biophys. Res. Commun. 2002, 294, 116.

(8) (a) Zhao, X.; Hilliard, L. R.; Mechery, S. J.; Wang, Y.; Bagwe, R. P.; Jin, S.; Tan, W. Proc. Natl. Acad. Sci. U.S.A. 2004, 101, 15027. (b) He, X.; Duan, J.; Wang, K.; Tan, W.; Lin, X.; He, C. J. Nanosci. Nanotech. 2004, 4, 585.

(9) (a) Andersson, J.; Rosenholm, J.; Areva, S.; Lindén, M. Chem. Mater. 2004, 16, 4160. (b) Horcajada, P.; Rámila, A.; Pérez-Pariente, J.; Vallet-Regí, M. Microporous Mesoporous Mater. 2004, 68, 105. (c) Charnay, C.; Bégu, S.; Tourné-Péteilh, C.; Nicole, L.; Lerner, D. A.; Devoisselle, J. M. Eur. J. Pharm. Biopharm. 2004, 57, 533. (d) Muñoz, B.; Rámila, A.; Pérez-Pariente, J.; Díaz, I.; Vallet-Regí, M. Chem. Mater. 2003, 15, 500. (e) Vallet-Regí, M.; Rámila, A.; del Real, R. P.; Pérez-Pariente, J. Chem. Mater. 2001, 13, 308.

(10) Lai, C.-Y.; Trewyn, B. G.; Jeftinija, D. M.; Jeftinija, K.; Xu, S.; Jeftinija, S.; Lin, V. S.-Y. J. Am. Chem. Soc. 2003, 125, 4451. of cholestane from coumarin-modified MCM-41. A mesoporous silica-based gene transfection system where the average particle size was $250 \mathrm{~nm}$ was also reported very recently. ${ }^{12}$ Mesoporous silica is thus believed to have great potential to be a new controlled-release system. At the same time, the extensive internal structure may be utilized for carrying non-releasing molecular imaging agents, such as fluorophore or magnetic resonance imaging (MRI) contrast agent. Previously, we reported gadolinium (Gd) incorporated nanosized mesoporous silicas as a new MRI contrast agent. ${ }^{13}$ In this paper, we will functionalize nanosized mesoporous silicas to be used as a fluorescence cell tag. Because of the protection of the mesopores, the embedded fluorophores are expected to be stable against enzymatic digestion and thus good for long time cell tracking.

Minimization of particle size to the nanometer range for intracellular delivery is critical in the biological usage of mesoporous silica because most cell uptake occurs in this size range. Several synthetic strategies to control the sizes of mesoporous nanoparticles have been reported. ${ }^{14-17}$ Small particles with diameters less than $50 \mathrm{~nm}$ often have disordered mesostructure, yet well-ordered mesoporous nanoparticles are relatively large in size. Although a recent report by Suzuki et al. ${ }^{18}$ described their success in the synthesis of well-ordered mesostructured particles with a diameter of $20-50 \mathrm{~nm}$, serious interparticle aggregation was present; this is a great handicap for their biological applications. In this communication, we demonstrate that the dye-functionalized well-dispersed nanoparticles in solution, with crystal-like facets, could undergo internalization into cells with high efficiency and consequently be used as a marker in cell tracking and in drug delivery.

Green emitting fluorescein dye attached mesoporous silica nanoparticles (FITC-MSNs) with well-ordered hexagonal pore structure were synthesized under dilute tetraethoxy orthosilicate (TEOS) and low surfactant conditions with $\mathrm{NH}_{4} \mathrm{OH}$ as a catalyst in a specially designed two-step preparation. The dye-functionalized mesoporous silica nanoparticles were prepared by co-condensation. First, $N$-1-(3-trimethoxysilylpropyl)- $N^{\prime}$-fluoresceyl thiourea (FITC-APTMS) was formed by stirring fluorescein isothiocyanate (FITC) in ethanolic 3-aminopropyltrimethoxysilane (APTMS) solution (the amount of APTMS was 9 mol \% of TEOS and was in

(11) (a) Mal, N. K.; Fujiwara, M.; Tanaka, Y. Nature, 2003, 421, 350. (b) Mal, N. K.; Fujiwara, M.; Tanaka, Y.; Taguchi, T.; Matsukata, M. Chem. Mater. 2003, 15, 3385.

(12) Radu, D. R.; Lai, C.-Y.; Jeftinija, K.; Rowe, E. W.; Jeftinija, S.; Lin, V. S.-Y. J. Am. Chem. Soc. 2004, 126, 13216.

(13) Lin, Y.-S.; Hung, Y.; Su, J.-K.; Lee, R.; Chang, C.; Lin, M.-L.; Mou, C.-Y. J. Phys. Chem. B 2004, 108, 15608.

(14) Lu, Y.; Fan, H.; Stump, A.; Ward, T. L.; Rieker, T.; Brinker, C. J. Nature 1999, 398, 223.

(15) Fowler, C. E.; Khushalani, D.; Lebeau, B.; Mann, S. Adv. Mater. 2001, $13,649$.

(16) (a) Cai, Q.; Luo, Z.-S.; Pang, W.-Q.; Fan, Y.-W.; Chen, X.-H.; Cui, F.-Z. Chem. Mater. 2001, 13, 258. (b) Nooney, R. I.; Thirunavukkarasu, D.; Chen, Y.; Josephs, R.; Ostafin, A. E. Chem. Mater. 2002, $14,4721$.

(17) Lin, H.-P.; Tsai, C.-P. Chem. Lett. 2003, 32, 1092.

(18) Suzuki, K.; Ikari, K.; Imai, H. J. Am. Chem. Soc. 2004, 126, 462. 


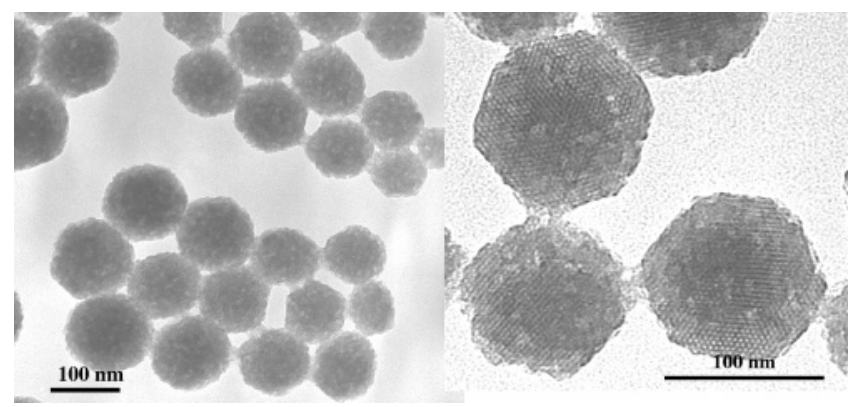

Figure 1. TEM images of the as-synthesized FITC-MSNs prepared at 40 ${ }^{\circ} \mathrm{C}$. The morphology and interior structure of the as-synthesized products were examined with a JEOL-JSM-1200EX II transmission electron microscope operating at an acceleration voltage of $80 \mathrm{kV}$.

larger excess than that of FITC) in the dark for $24 \mathrm{~h}$. Separately, cetyltrimethylammonium bromide (CTMAB) was dissolved in $0.5 \mathrm{M} \mathrm{NH}_{4} \mathrm{OH}(\mathrm{pH}=11.3)$ at 40 or $50^{\circ} \mathrm{C}$, and $0.2 \mathrm{M}$ dilute TEOS (in ethanol) was added with stirring. The stirring was continued for $5 \mathrm{~h}$, then FITC-APTMS was added, and more dilute ethanolic TEOS was added with vigorous stirring for $1 \mathrm{~h}$. The solution was then aged at 40 or $50{ }^{\circ} \mathrm{C}$ for $24 \mathrm{~h}$. The final $\mathrm{pH}$ of the nanoparticle suspension decreased to 9 . The molar ratio of the reaction mixture was $3000 \quad \mathrm{H}_{2} \mathrm{O}: 28.35 \quad \mathrm{NH}_{3}: 27.55 \quad \mathrm{C}_{2} \mathrm{H}_{5} \mathrm{OH}: 1.00 \quad$ TEOS:0.31 CTMAB. Samples were collected by centrifuging at 12000 rpm for $20 \mathrm{~min}$, washed, and redispersed with deionized water and ethanol several times. The solid products were obtained by centrifuge and dried in the centrifuge tube at 60 ${ }^{\circ} \mathrm{C}$ overnight. The surfactant templates were removed by extraction in acidic ethanol $(1 \mathrm{~g}$ of $\mathrm{HCl} / 50 \mathrm{~mL}$ of ethanol, $24 \mathrm{~h})$.

By separating the nuclei formation and particle growth into two steps in dilute alkaline solution, well-dispersed nanoparticles were formed. The yield of the hexagonal shape was high, and the size was quite uniform. The transmission electron microscope (TEM) images showed that both the assynthesized and surfactant-free FITC-MSNs were composed of large numbers of discrete mesostructured nanoparticles (Figure 1 for the as-synthesized, and Figure S1 of the Supporting Information for the surfactant-removed nanoparticles). These nanoparticles were uniform in size (about 110 $\mathrm{nm}$ when synthesized at $40{ }^{\circ} \mathrm{C}$, Figure 1a) and had welldefined hexagonal facets, as can be seen in the highmagnification TEM (HR-TEM) image (Figure 1b). The internal mesoporous structure is well-ordered, consistent with the sharp XRD peaks observed. Scanning electron microscope (SEM) images (see Supporting Information, Figure S2) also showed that FITC-MSNs displayed hexagonal crystal-like morphology.

The mesostructure of the samples before and after template removal were examined by X-ray powder diffraction (XRD) (see Supporting Information, Figure S3). All XRD patterns exhibited three hexagonal characteristic reflection peaks (100), (110), and (200). The $d_{100}$ spacing of extracted FITCMSN was $3.86 \mathrm{~nm}$. The physical properties of these mesoporous silica nanoparticles were analyzed by $\mathrm{N}_{2}$ adsorption-desorption isotherms (see Supporting Information, Figure S4 and Table S1); the surface area $\left(910 \mathrm{~m}^{2} \mathrm{~g}^{-1}\right)$, pore volume $\left(0.69 \mathrm{~cm}^{3} \mathrm{~g}^{-1}\right)$, and BJH pore size distribution (2.5 $\mathrm{nm}$ ) were obtained. The FITC-MSNs exhibited characteristic

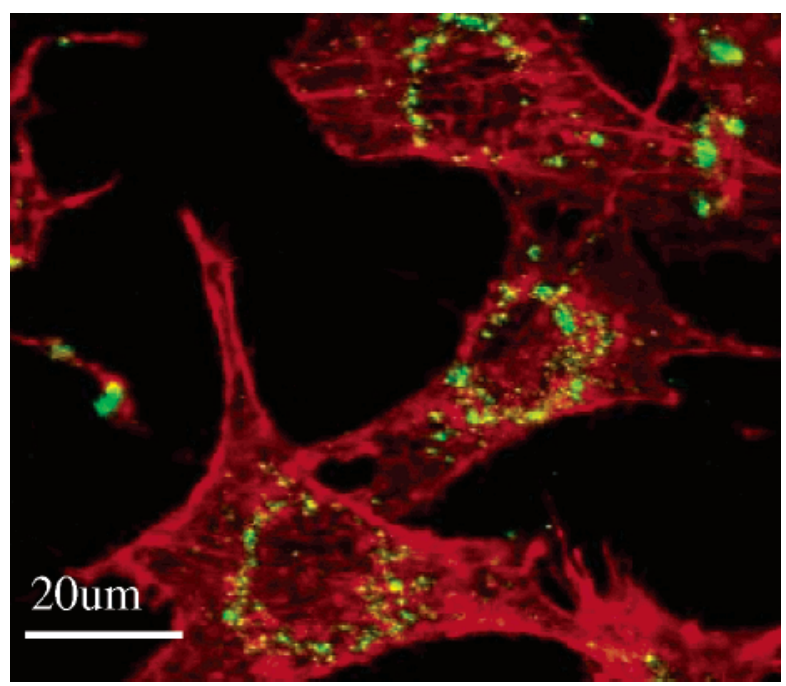

Figure 2. Confocal images of FITC-MSNs (green) in 3T3-L1 cells; cell skeleton was stained with rhodamine phalloidin (red). Cells were incubated with FITC-MSNs for $1 \mathrm{~h}$, washed, and further incubated in particle-free medium overnight.

type IV BET isotherms, and no hysteresis loop was observed. In addition, the secondary adsorption step at $0.95 P / P_{0}$ was attributed to the macropores formed among the nanoparticles. A typical fluorescein emission spectrum was also displayed by these particles. The as-synthesized mesoporous nanoparticles were very stable and remained suspended in aqueous solution for more than 6 months.

Cellular uptake of surfactant-free FITC-MSNs was investigated by confocal microscope, TEM, and flow cytometry. 3T3-L1 fibroblast cells were cultured onto glass coverslips in Dulbecco's modified Eagle's medium (DMEM) containing $10 \%$ fetal bovine serum (FBS) and pen/strep (penicillin/ streptomycin) at $37{ }^{\circ} \mathrm{C}$ in $5 \% \mathrm{CO}_{2}$ and $95 \%$ air. After $24 \mathrm{~h}$ of cell attachment, cells were treated with FITC-MSNs for $1 \mathrm{~h}$ at $37^{\circ} \mathrm{C}$ in serum-free medium followed by phosphatebuffered saline (PBS) wash, and then further incubated in particle-free medium overnight. Treated cells were fixed with $4 \%$ paraformaldehyde and mounted for optical and confocal microscope examinations. The confocal images (Figure 2) showed that the nanoparticles have crossed the cell membrane and were internalized into cells, most likely through endocytosis. The green fluorescence of FITC can be clearly seen in cytoplasm especially around the nucleus. The green FITC appears localized as discrete dots, which indicate that they reside inside the MSNs without much leaching. The uptake began efficiently as early as 10 min after incubation and was relatively rapid within the first $1-2 \mathrm{~h}$ of incubation. The amount of nanoparticles engulfed by the cells increased with the amount of the nanoparticles in the culture medium and the incubation time saturated at $4 \mathrm{~h}$. For the cell retention examination, cells were incubated with FITC-MSNs for $1 \mathrm{~h}$ at $37^{\circ} \mathrm{C}$, washed, and further incubated in nanoparticle-free growth medium with $10 \%$ FBS and pen/strep for 1, 3, and $5 \mathrm{~d}$. Figure 3 shows the time evolution of the cells labeled with FITC-MSNs. As the cell growth progressed, less FITCMSNs were detected inside the cells. However, there were still easily detectable amounts inside the cells on day 5 . The internalization of FITC-MSNs is further confirmed with TEM examinations. Cells were incubated with FITC-MSNs for 1 

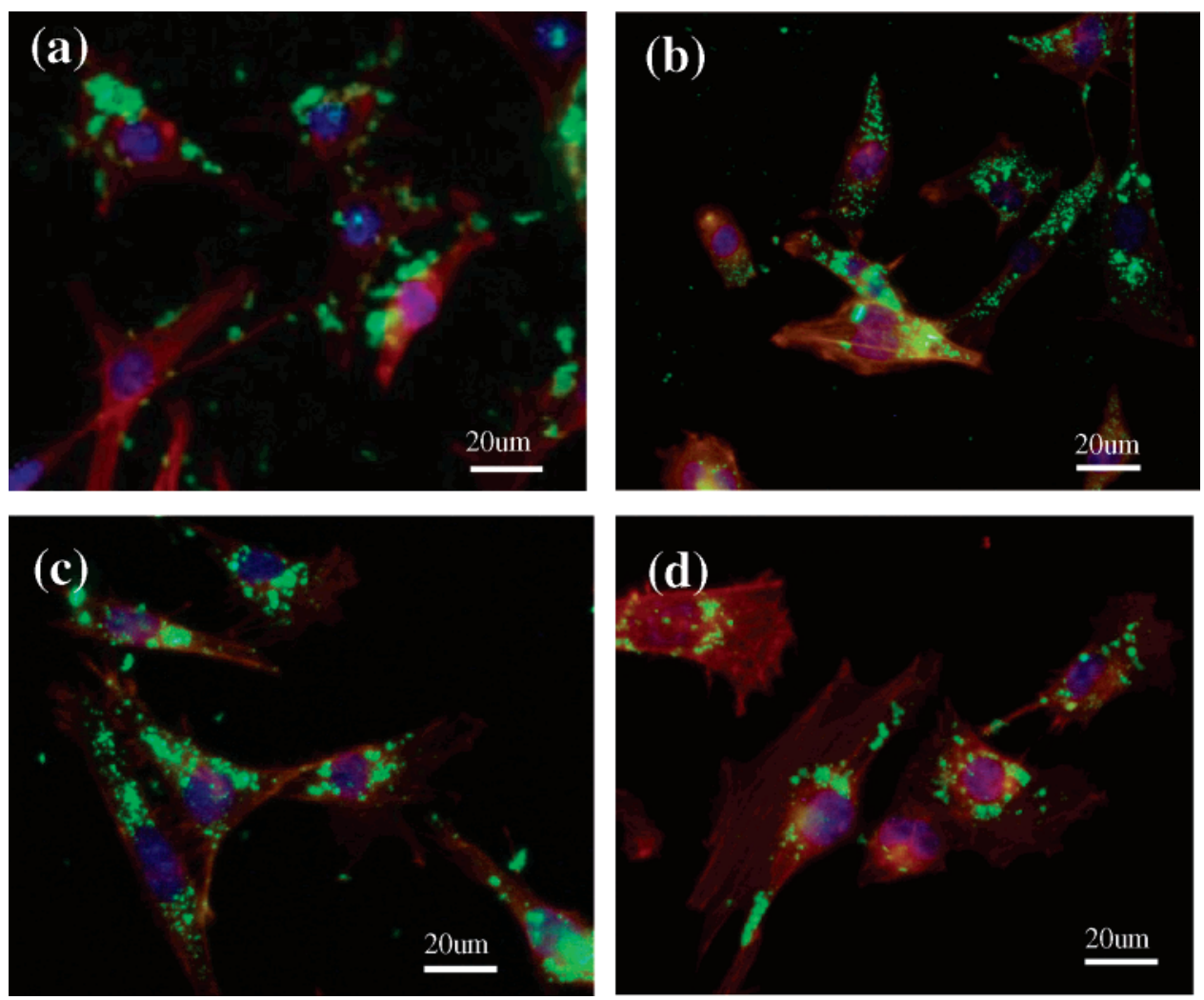

Figure 3. Time-course confocal images of 3T3-L1 cells labeled with FITC-MSNs (green emitting), cell skeleton was stained with rhodamine phalloidin (red), and cell nucleus with DAPI (purple). Cells were incubated with FITC-MSNs for $1 \mathrm{~h}$, washed, and further incubated in particle free medium for (a) $0 \mathrm{~h}$, (b) $1 \mathrm{~d}$, (c) $3 \mathrm{~d}$, and (d) $5 \mathrm{~d}$.

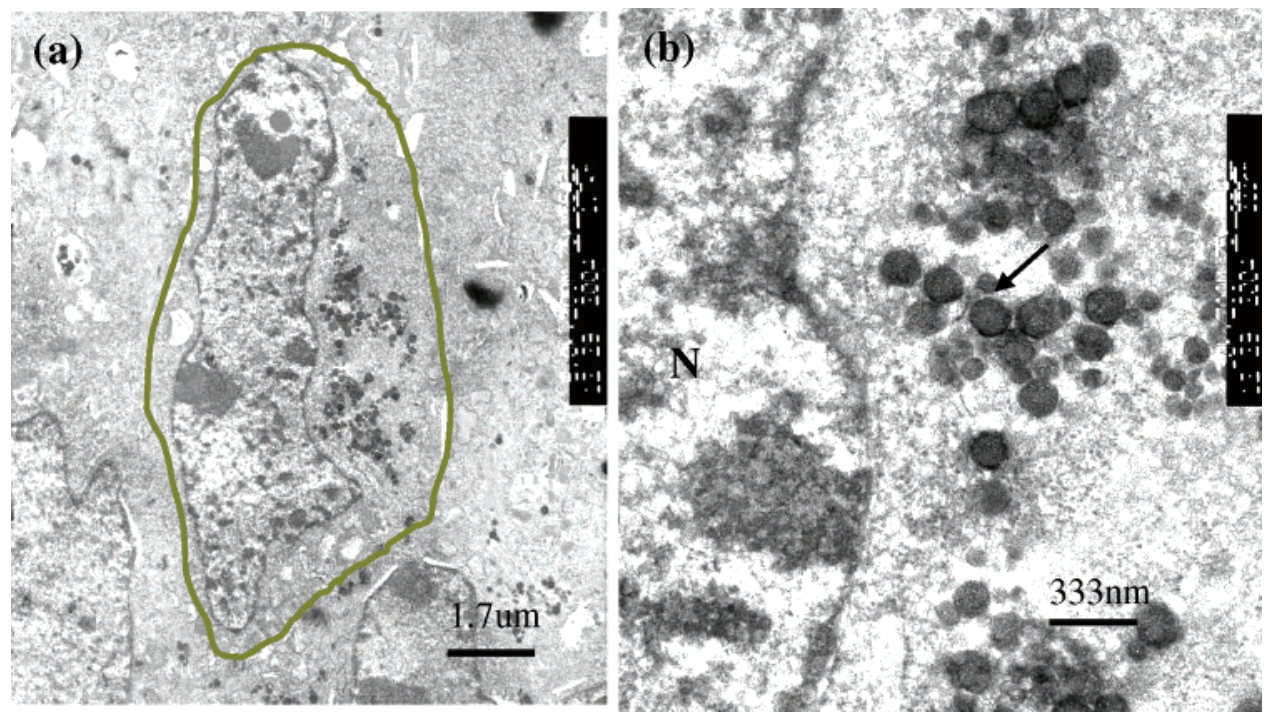

Figure 4. TEM images demonstrate the presence of FITC-MSNs in the 3T3-L1 fibroblast cells after incubation with FITC-MSNs for 1 h, N, nucleus; the brown line in panel a is an outline of one cell.

$\mathrm{h}$ at $37^{\circ} \mathrm{C}$, washed, and fixed with $2.5 \%$ glutaraldehyde. Figure 4a,b showed the TEM images of intracellular FITCMSNs, which indicated that the particles have entered cells; however, they did not penetrate the nuclear membrane, instead they accumulated in cytoplasm. The hexagonal morphology and the integrity of the porous structure of the nanoparticles were retained as shown in the TEM image of ultrathin sectioned sample (Figure 4b, arrowhead). Flow cytometry data also indicated that FITC-MSNs could enter 3T3-L1 cells efficiently (Figure 5). Although flow cytometry cannot distinguish between surface-bound and intracellular nanoparticles, confocal and TEM data do confirm the uptake of the nanoparticles by the cells. Furthermore, steps were taken to wash away the surface-bound nanoparticles and ensure that data from flow cytometry were due to the engulfed nanoparticles. ${ }^{19}$ Although the time-course retention investigation showed decay in flow cytometry examinations, a small fraction of FITC-MSNs-postive cells was still detectable up to $3 \mathrm{~d}$ (Figure 5, arrow). The results of both

(19) Richard, J. P.; Melikov, K.; Vives, E.; Ramos, C.; Verbeure, B.; Gait, M. J.; Chernomordik, L. V.; Lebleu, B. J. Biol. Chem. 2003, 278 , 585 . 

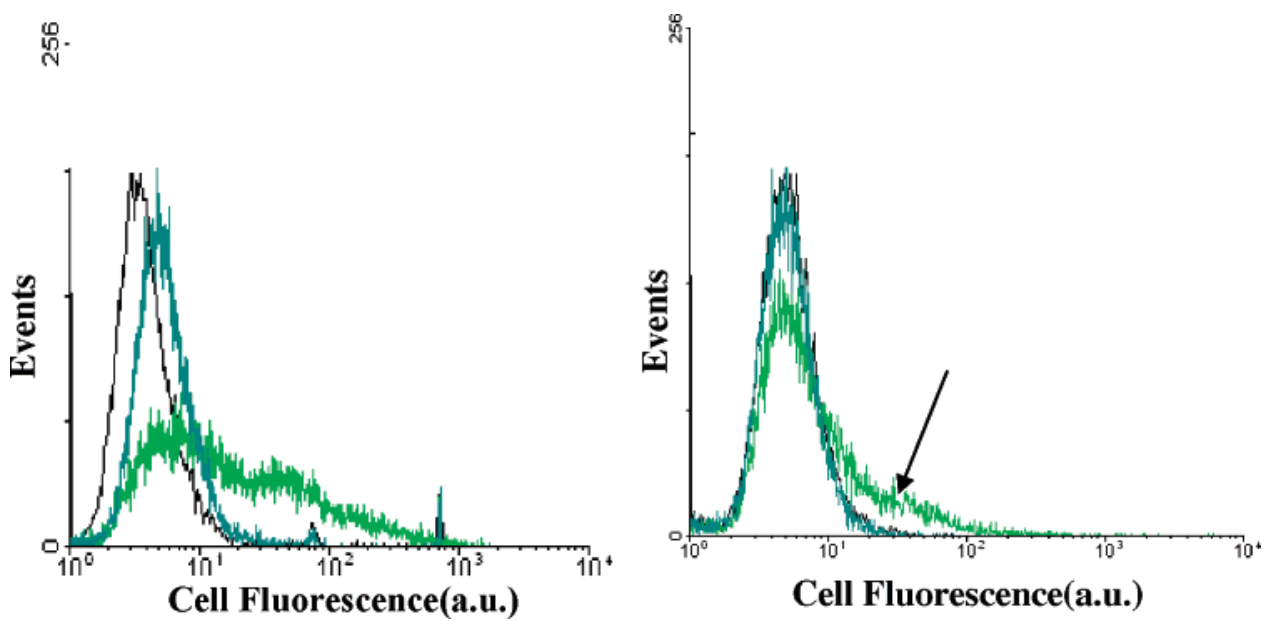

Figure 5. Flow cytometry analysis for the FITC-MSNs accumulated in 3T3-L1 cells. Cells treated with vehicle as control, with FITC-MSNs and with free FITC dye were displayed in black, green, and blue curves, respectively. Left panel: cells were allowed $24 \mathrm{~h}$ for growth after FITC-MSNs treatment; right panel: cells were allowed $72 \mathrm{~h}$ for growth after FITC-MSNs treatment.

confocal microscope and flow cytometry examinations showed that fewer FITC-MSNs-postive cells were observed at day 5 after treatment. The decrease could be due to cell proliferation where the increased number of cells would dilute the fluorescence intensity and reduce the number of nanoparticles in each cell and exocytosis of the nanoparticles, which has been observed with silver-enhanced gold nanoparticles on single living cells. ${ }^{20} \mathrm{~A}$ direct comparison of the photostability between FITC-MSNs and FITC conjugated anti-mouse IgG antibody inside the cells (Supporting Information, Figure S4) showed that the FITC-MSNs were more stable, about 2.5 times more than the antibody conjugated dye. Cytotoxicity of the dye-labeled nanoparticles was examined by MTT assay. ${ }^{21}$ Cell viability was not affected when cells were treated with nanoparticles of $0.85 \mathrm{wt} \%$ and below (data not shown). The cellular internalization of FITCMSNs appears to be a general phenomenon for both adherent (3T3-L1, MCF7, HeLa, and hMSC) and nonadherent (HSC) cells (see Supporting Information for confocal images of other cells with FITC-MSNs inside, Figure S6). ${ }^{22}$

In summary, well-dispersed dye functionalized hexagonal crystal-like mesoporous nanoparticles were synthesized with high yield under dilute conditions, and the cell labeling

(20) Xu, X.-H. N.; Chen, J.; Jeffers, R. B.; Kyriacou, S. Nano Lett. 2002, 2,175

(21) The MTT assay is a colorimetric assay that measures the reduction of a yellow tetrazolium component ((3-(4,5-dimethylthiazol-2-yl)-2,5diphenyltetrazolium bromide, MTT) into an insoluble purple formazan product by the mitochondria of viable cells.

(22) Tsai, C.-P.; Huang, D.-M.; Kuo, C.-T.; Hung, Y.; Chen, Y.-C.; Mou, C.-Y. (unpublished). capability was demonstrated. For the first time, these FITC functionalized mesoporous silica nanoparticles with sizes around $110 \mathrm{~nm}$ were demonstrated to be internalized into 3T3-L1 fibroblast cells and to accumulate in cytoplasm. The mesoporous silica nanoparticles appear to have no apparent cytotoxic effects on the fibroblast cells. The cellular internalization appears to be generic for various cells. In addition, the mesoporous nanoparticles are versatile for many further developments. Silica can be easily derivatized to bind to antibodies, proteins, etc.; hence, targeted agents are possible, which we are actively pursuing. The internal pores and its surface functionalization can be exploited for drug delivery. We are investigating the detailed cell uptake mechanism of these FITC-MSNs because it is important for drug delivery. Thus, we suggest that these silica nanoparticles with large internal space are promising to serve as a carrier for further studies in biological applications.

Acknowledgment. This research was supported by a grant from the National Research Council, Taiwan (NSC-93-2120M-002-003). We thank Ms. Yun-ju Chang for her help with the confocal microscope examinations.

Supporting Information Available: Characterization of the FITC-MSNs such as TEM and SEM images, XRD patterns, and $\mathrm{N}_{2}$ adsorption-desorption isotherms, photostability comparison with FITC conjugated anti-mouse IgG antibody, and confocal images of other cells with FITC-MSN inside. This material is available free of charge via the Internet at http://pubs.acs.org.

CM051014C 